\title{
Introduction
}

The essays presented here were not written to a program, certainly not to the program of developing a theory of liberalism or a liberal political theory. The terms liberal and liberalism are prominent in all of them, however, and a number of the themes that recur in the essays can be viewed as within or about liberal theory and practice. In bringing the essays together in this format, I hope to underline these themes and to this extent move "toward a liberalism."

I should say at the outset that the presence of these features and the fact that the same terms and themes appear with increasing frequency in books that I have written in roughly the same period as these essays ${ }^{1}$ come initially as - if I may put it this way-something of a surprise to me. This is not because I have deceived myself about my disposition to some form of liberalism in practical politics. The surprise is due, rather, to the conjunction of the conception of political and moral philosophy in which I have been working over the past couple of decades and an understanding of liberalism which I have-perhaps less self-consciously—accepted.

The conception of philosophy, for which "analytic" is a usual if no longer especially helpful tag, has tended to produce differentiating, disaggregative studies rather than the more encompassing, synoptic formulations commonly associated with ideological thinking.

${ }^{1}$ Richard E. Flathman, The Practice of Rights (New York: Cambridge University Press, 1 976); The Practice of Political Authority (Chicago: University of Chicago Press, I 980); and The Philosophy and Politics of Freedom (Chicago: University of Chicago Press, I 987). 


\section{Toward a Liberalism}

At least for this reason, commitment to this conception of philosophizing would not seem to predict the use of ideological terms such as liberal and liberalism as thematic or organizing categories.

My understanding of liberalism has both historical and doctrinal components. As to the first, liberalism has never been a closely integrated or firmly fixed doctrine; its proponents have held to a considerable and frequently changing variety of views and its historians and critics have regularly disagreed concerning its main ideas and tendencies. As to the second, suspicion of systematic, programmatic, certainly dogmatic theorizing has been a persistent characteristic of liberal thought and practice. In the first essay I argue against the view that is most often invoked, at least by the philosophically inclined, to explain this characteristic, namely, that liberalism is wedded to philosophical empiricism and its attendant atomism and skepticism. ${ }^{2}$ Notwithstanding this argument, however, many prominent liberals have been empiricists and numerous others have insisted on the empirical, skeptical, individualist, and pluralist character of the liberal outlook. If I am correct in my understanding that these characteristics and the antisystematic tendency that frequently accompanies them are prominent in liberalism, we will expect to find its themes in the ideational elements of liberal practices and in the writings of liberal publicists, not in the treatises of philosophers.

Viewed in this perspective, the project represented by this collection has a certain anomalous quality. On further reflection, however, I have found my initial surprise and discomfort giving way to the view, or at least to recognition of the possibility, that the emergence of the language and the themes of liberalism in my work is in part a natural result of the very conjunction that at first made it seem surprising and doubtful to me. This is not, or not exactly, for the reasons that have been advanced for thinking that the conception of philosophy in question is inherently conservative and, given that liberalism is the dominant ideology in the culture in which the conception has found favor, has perforce gravitated toward a defense of liberalism. ${ }^{3}$ Apart from the most general questions raised by explanations of this sort, there are a number of specific difficulties with this argument. On any reading of its history, the advent

2See, for example, Bertrand Russell, Philosoṕhy and Politics (London: Cambridge University Press, 1947).

3See, for example, Herbert Marcuse, One-Dimensional Man (Boston: Beacon Press, 1964); Ernest Gellner, Words and Things (Boston: Beacon Press, 1959). 
of liberalism substantially antedates the emergence of analytic philosophy; numerous liberal thinkers are decidedly not of an analytic orientation in their philosophizing and numerous analytic philosophers are opposed to liberalism; liberalism was initially, and in some settings remains, a radical not a conservative or an establishment view. And so forth.

Nevertheless, if the above characterizations of "analytic" philosophy and of liberalism are accurate, there may now be a greater consonance, perhaps even an affinity, between the two than between such philosophizing and any of the other currently influential ideologies. Analytic moral and political philosophers are committed to a close examination of the language actually employed in moral and political discourse, language that in our culture has been substantially influenced by liberalism. For this reason, and whatever moral and political convictions they may hold or conclusions they may reach, the work of philosophers of this orientation will concern, and to that extent may have a tendency to sustain, conceptions prominent in liberal theory and practice. More important here, on the variant of this understanding of philosophy that I find most congenial - that is, the Wittgensteinian - the philosopher's stance toward the language (and hence the practices) of moral and political discourse is at least akin to that which much liberalism urges us to maintain toward persons and sometimes even toward social groups and associations, namely, a respectful stance. (I explore this complex and importantly problematic comparison in the first essay.) Finally, insofar as liberalism is a cautious, skeptical, or antisystematic ideology, if any mode of philosophizing is congenial to it, the analytic is a promising candidate.

These last considerations help to relieve my concern that the present project is, at a very general level and hence pervasively, incongruous or even aberrant. They should also begin to prepare the reader for what might be called the immodest modesty of the several essays and of the collection as a whole. I continue this process by introducing in more substantive terms some of the main themes of the papers that follow.

The first of these themes, which manifests both the "modest" and the "immodest" elements in "immodest modesty," concerns the circumscribed possibilities of moral and political philosophy, especially as regards their role in political practice and more especially their role in political practice in liberal societies.

In its most general formulation, for which I draw heavily on 


\section{Toward a Liberalism}

Wittgenstein, this theme involves claims about philosophy sans phrase. Although not passive, philosophy is primarily reactive in the sense that its materials and issues (and hence its possibility and its limits) are for the most part given to it, not created or constructed by it, given to it by thought and action that may come to be influenced by philosophizing but that are not themselves philosophical in character. In its application to moral and political philosophy, this general formulation is augmented by an understanding of what has traditionally been called practical as distinct from theoretical reasoning. It is further augmented in regard to liberal societies by the normative argument concerning "respect" (in something like the sense of "a decent respect for the opinions of mankind") already mentioned.

This theme is cleveloped in the first essay and it is elaborated and applied, partly by way of criticizing the overweening ambitions of other moral and political philosophers, in the essays on freedom, citizenship, equality, and moderating rights. It represents "immodest modesty" of a kind familiar from various forms of skepticism: in insisting on a modest role for philosophy in moral and political practice, it perpetrates the immodesty of specifying the character and the limits of moral and political philosophy.

A consonant theme, or perhaps tendency, is represented in a form familiar from the history of liberalism by the essay on authority, in less familiar forms in the essay on citizenship, and in the several discussions of rights and of equality that occur in the volume. Liberals have been less suspicious of authority than they have been of power, and some among them have turned readily to authority not only to control power but to legitimate it and put it to effective use in pursuing their social and political objectives. The uneasiness about authority which is expressed in my essay is more characteristic of emphatically individualist liberal writers, particularly those who lean toward libertarianism, toward some version of laissezfaire doctrine, and of course it is also characteristic of those few (such as myself) who regard anarchism as a powerfully attractive ideal. It is less common to link citizenship to authority and power and to use that linkage, as I do in the third essay, as reason for what I call a chastened view concerning citizenship and especially concerning participationist and communitarian theories of citizenship and of democracy.

It is yet less common to draw parallels between authority and 
rights and to caution that rights-including rights to liberties that are (rightly) prized by most liberals and to forms of equality promoted by many liberals-need to be "moderated" lest they become weapons against values that many liberals have cherished. In one perspective, my arguments in these regards (especially my objections to so-called natural or otherwise absolute and inalienable rights and to libertarianism) are instances of the mildly skeptical, antisystematic, and antienthusiasm tendency of my entire discussion. In another, and especially in respect to rights, they reflect a desire to acknowledge and sustain deontological features of our morals and politics while accommodating them to the contextualist, pluralist, and consequentialist strains in the liberal tradition (strains that seem to me to provide welcome justification not only for civil disobedience to established authority but for what I call "civil encroachment" on established rights).

To elaborate somewhat, both rights and authority appear to be "content-independent" in the sense in which H. L. A. Hart used that characterization of rights: ${ }^{4}$ rights and authority, especially in political life, are typically established through procedures such as promising, authorizing, subscribing, and consenting, procedures that are used to create, often into the indefinite future, entitlements not merely to this or that particular action at such and such times and places but to classes of actions taken or not at the discretion of all agents or agencies to whom or to which the right or the authority has been assigned. They are content-independent in that a great variety of entitlements, and corresponding duties, obligations, and so forth, can be created by use of these procedures and devices and that the entitlements and duties result from the correct or valid use of the procedure not from the merits of the actions or their consequences. Although valuable, arguably indispensable, features of our moral and political arrangements, these devices are nevertheless objectionable on theoretical grounds and are readily and frequently abused in even the best of the practices that include them. Political and moral philosophers, perhaps particularly philosophers of a liberal bent, have contributed importantly to clarifying these notions and to defending them against utilitarianism and various forms of collectivism, communitarianism, and traditionalism. My purpose is not to undo this work but to qualify what seem to me

4See H. L. A. Hart, “Are There Any Natural Rights?” Philosophical Review 64 (I955): I75-9I. 


\section{Toward a Liberalism}

unjustifiably strong conclusions that have been drawn from it. (I hope that the essay on abortion will testify to my belief in the value of the institution of individual rights. I see no reason to amend the main arguments or conclusions of that essay, but were I to rewrite it I would give greater emphasis to the provisions it makes-see especially pp. 200-204-for "moderating" the moral and legal right to abortion on demand. Doing so would diminish the tensions between the essay and the conception of the theory-practice relationship that informs the book.)

Much of my attempt to harmonize deontological and consequentialist (but not, I now think, utilitarian) considerations is carried out through discussions of what I call the liberal principle, or LP. I advanced this principle in The Practice of Rights; I argued for and from it in The Philosophy and Politics of Freedom; and it figures prominently in several of these essays. LP states that "it is a prima facie good for persons to form, to act on, and to satisfy and achieve desires and interests, objectives and purposes." My argument for the principle is naturalistic (hence immodest?) in the sense that it relies on claims about the usual characteristics of human beings and their circumstances, but it is also contextualist or culture-specific rather than transcendental or universalistic in that my claims about the characteristics and about what should be inferred from them are limited (!) to societies of Western modernity (hence modest?).

As is indicated by "principle," LP is intended to be (weakly) deontological; I argue that it should regulate thought and action in the very wide area of its applicability. This means that criticisms and condemnations of interests and desires, objectives and purposes, and their satisfaction, and attempted interferences with actions to serve and achieve them, require justifications sufficient to remove the onus that LP places on them. As indicated by "prima facie" and "good," however, LP is, in a logical sense, a weak principle; the good that it identifies gives way to adequately justified all-thingsconsidered judgments about better and best, right and wrong. Such judgments, moreover, while always liable to challenges based on LP, can and do become codified in moral rules, in laws, and in social conventions. If the processes and procedures of codification satisfy further, locally various criteria, they sometimes yield conclusionsfor example, that there should be certain rights and duties-which typically hold against whole classes of claims advanced on the basis of LP. Some conclusions of this kind (the conclusion that there is a 
duty not to commit murder or to inflict cruelty, for example) have become so widely and firmly accepted in our culture as generally to prevent or to deflect challenges to them and to place an exceptionally heavy burden of justification on those who nevertheless issue such challenges. In a society that accepts LP, however, all such conclusions are, in reason, subject to questioning proceeding from LP.

It is at least initially plausible to think of LP as stating a right to form and to act to satisfy desires and interests, objectives and purposes, and as stating a correlative duty not to interfere when others do so. The principle bears at least some resemblance to farreaching notions such as the right to equal consideration, the right to consideration as an equal, and the like. It is yet closer kin, especially if we focus on conceptual form rather than the ideational substance poured into that form, to the "natural right" that Hart claimed is presupposed and qualified by the "special rights" that are created by procedures such as contracting and promising, to Hobbes's "Natural Right" to all the things I judge necessary to my well-being, and to Hohfeld's concept of "liberties" that correlate with "no-rights." 5

We do better, however, to think of LP as a principle (as an element in our axiology or our set of authoritative values and beliefs) from which to reason for or against rights and duties and for or against construals and implementations of rights and duties. The essay on abortion and, in part, the essay on freedom argue from LP to the conclusion that there should be a right to abortion on demand and rights to certain liberties; and the essay on freedom and the one titled "Moderating Rights" invoke LP against various rigorist or unjustifiably strong deontological views of rights. This argumentation would be hampered, at least in the sense that the conceptualization in which it is presented would be much more complicated and might appear to be internally contradictory, if LP were treated as itself an asseveration of rights and duties.

My reasonings for and from LP are compressed expressions of the individualism, pluralism, and teleological thinking represented in various forms in these pages. The interests, desires, and so forth that

5See Hart, "Are There Any Natural Rights?"; Thomas Hobbes, Leviathan (Oxford: Basil Blackwell, I 955); Wesley Hohfeld, Fundamental Legal Concepts (New Haven: Yale University Press, I919). On these points, see also my Practice of Rights. 


\section{Toward a Liberalism}

LP protects, and the liberties and rights that are partly grounded in LP, are, first and foremost, formed and pursued, enjoyed and exercised, by individual persons. In treating individual persons and their good as the primary "unit" of thought and of evaluation, I align myself with the individualist strain in liberalism. One form of pluralism enters the discussions in my recognition that the interests and desires that individuals form are in important part the result of the location of those individuals in one of the many differing cultural traditions and societies and, more proximately, their associations and interactions with groups of individuals in their own cultures and societies. Neither the individuals nor the individualism presented here is "atomic" or "atomistic." Thus for important purposes the unit in and about which my theorizing occurs is not the individual but the culture or the society.

Individualism and pluralism of distinct but I think complementary kinds are represented here in a tendency toward a strong version of a view that is sometimes called voluntarism, sometimes antiperfectionism, sometimes other names. (In the sense in which I am using it, voluntarism was first a theological doctrine stressing the will and willfulness, and hence mysteriousness, of God and God's actions. God does as and because God wills, not as or because reason dictates. The following paragraphs, and further discussion in the next essay, indicate ways in which voluntarism in moral and political theory is a descendant of this theological view.)

In fact, individuals in modern Western societies, including in comparatively homogeneous and well-integrated societies and sectors of societies, form and pursue a considerable diversity of desires and interests, ends and purposes (conceptions of their good, as Rawls and others say). In varying degrees and on a variety of grounds, liberalism has approved and fostered this diversity and the understandings and arrangements that sustain and promote it. According to liberalism, individuals and groups not only do but should develop and pursue their conceptions of good "voluntarily," and where this is the case these conceptions have differed widely and can be expected to continue to do so.

It has not been a part of liberalism that this diversity and pluralism is, should, or could be without limit. By acculturation, socialization, and education, by example and argumentation, and through a varying but invariably substantial array of disciplinary and coercive devices, these societies evolve, adopt, and impose restrictions on the 
thought and action of their members. If as a generalization liberals have tended to be more suspicious of or cautious about these characteristics of modern Western societies, if they have tended to be selective concerning means of limiting diversity, they have denied neither the social and political importance of limitations nor the possibility of interpersonally convincing justifications for the particular limitations adopted and imposed. Liberalism is not radical antinomianism or individualist anarchism and, despite their voluntarism, few liberals have embraced doctrines as deeply subjectivist as emotivism or Sartrean existentialism. In these respects, the present essays are well within the liberal tradition.

But liberals have disagreed with one another concerning the appropriate scope or extent of restrictions on diversity and-more important here-concerning the best justifications for such limits. A word about these disagreements, a number of which are more fully aired in the essays that follow, will help further delineate "voluntarism" and the forms of individualism and pluralism that it involves.

In societies that in fact are diverse and pluralistic, endorsement of LP itself involves a weak form of voluntarism. But we might endorse LP for certain purposes and nevertheless think that we have or could in principle develop norms or principles that are-in fact, in truth, or in reason-unqualifiedly and indisputably superior to LP. If (I) those norms are thought applicable to a circumscribed range of thought and action they might be proposed as fixed qualifications of LP in that range or at least as shifting the burden of justification to those who propose to depart from them. In this case, LP would operate primarily if not exclusively outside of the ambit of the more highly ranked norms. Alternatively, (2) if we think that the valid or proper application of such norms is wide or even general, we might disavow LP altogether and seek to implement a thoroughgoing perfectionism or a strict deontology. While few would regard views of this sort as liberal in character, a liberal might entertain these possibilities but promote the superior norms or principles by example, argument, education, and the like, sustaining commitment to LP on the ground that it would be impossible or too costly to enforce the norms.

These possibilities are presented in concrete terms in a number of doctrines that are often regarded as liberal. Theorists of natural rights from John Locke on exemplify (I) in that they regard appeals to LP (or any comparable principle) as circumscribed by the natural 


\section{Toward a Liberalism}

rights and duties. By contrast, John Rawls's "Kantian constructivism" eschews the idea of natural rights and clearly adopts a voluntarist position concerning thought and action outside of the "basic structure" of society. Beyond the confines of that structure, Rawlsian liberalism presumes a wide and in any case an ineliminable diversity of conceptions of good. Within that structure, however, Rawls's view is akin to Locke's in proposing principles of justice that are to have "absolute weight" against all other considerations and hence against LP. As to (2), it is perhaps most clearly represented by religious thinkers who have no doubt about the superiority of their religious beliefs or the moral implications of those beliefs but who nevertheless promote toleration of a diversity of religious beliefs and practices in order to avoid the destructive conflicts that they believe invariably result from attempts to impose religious-cum-moral uniformity.

As it is understood here, voluntarism refuses these possibilities, but only in the sense that it rejects the idea that the rights, norms, principles, and the like have or could in principle be provided with incorrigible or indisputable foundations. On the one hand, rights, norms, and the like might in fact be undisputed in the society, and voluntarist liberals might have no actual, no "live," disposition to dispute them. On the other hand, voluntarism rejects the possibility that they are or could be put beyond cogent disputation. (Of course Rawls allows for dispute concerning his principles of justice, but he argues that consideration of them is fruitful only in the "original position and under the constraints of the "veil of ignorance." Once the principles are adopted, they can be reconsidered only by returning to that position and its constraints.)

A full development and defense of voluntarism would have to justify the particular "immodest modesties" that it involves. A leading instance is its claim that we can be certain that we cannot be certain about the justifiability of our moral and moral-cum-political conclusions. Yet worse, voluntarism makes this certain uncertainty into a kind of moral and political certitude, the certitude that we always are and will always be unjustified if we treat our moral and political conclusions as beyond cogent dispute. More proximately, development and defense of voluntarism would require showing how and why acceptance of it is consistent with commitment to regulative principles, even principles that are as "weak" as LP.

As I envisage it, such a development and defense would involve 
an elaboration, with particular reference to moral and political questions, of the Wittgensteinian understandings mentioned above. Moral and political certainties parallel to or at least analogous with the certainties Wittgenstein discusses in On Certainty and elsewhere are possible, ${ }^{6}$ but claims to and indeed the quest for the further, superstrong certainties that he discredits involve deep misunderstandings. The first essay in this book considers elements of Wittgenstein's view and of the related views of Michael Oakeshott, as do passages in several of the other essays, but I do not address these issues in a concerted manner here.

As already suggested, however, voluntarist views are prominent in liberal thought and do support forms of individualism and pluralism beyond those already discussed. John Stuart Mill's "fallibilism," together with his closely conjoined case for a rich diversity of "experiments in living," particularly as interpreted by Isaiah Berlin, is a leading example, and Berlin's own moral and political thinking another. ${ }^{7}$ As Berlin argues, Mill's individualism and pluralism are in sharp tension with the residues of classical utilitarianism in his thinking, and Berlin, Bernard Williams, Stuart Hampshire, and of course John Rawls are among numerous contemporary writers whose articulations of forms of voluntarism are by contrast with and in opposition to what they regard as the anti-individualist and homogenizing tendencies of utilitarianism. ${ }^{8}$ I examine the differences among these views (to say nothing of similarities and differences between them and the Nietzschean and post-Nietzschean positions they resemble in respects pertinent here) only to the extent of offering objections (mainly in the fourth essay) to Rawls's in many ways minimal restrictions on individualism and pluralism. I hope, however, that my arguments against Rawls will also challenge views more rigid and far-reaching than his and do something to indicate the lines along which an insistently voluntarist liberalism might be developed.

The tendencies in liberal theory and practice which the foregoing

6See Ludwig Wittgenstein, On Certainty (Oxford: Basil Blackwell, I969).

7See John Stuart Mill, On Liberty (New York: E. P. Dutton, I95 I); and Isaiah Berlin, Four Essays on Liberty, esp. essay 4 (Oxford: Oxford University Press, 1969).

8See Bernard Williams, Ethics and the Limits of Philosophy (London: Fontana Paperbacks and William Collins, I985); Stuart Hampshire, Morality and Conflict (Cambridge: Harvard University Press, 1983); John Rawls, A Theory of Justice (Cambridge: Harvard University Press, 1971). 


\section{Toward a Liberalism}

themes affirm are of course susceptible to various kinds of distortion and corruption. Individualism can degenerate into privatism, egoism, and hero-worshiping romanticism, voluntarism into irrational subjectivism, pluralism into corporatism and ethnocentricity, chauvinism, and other forms of parochialism. "Chastening" our thinking about citizenship and "moderating" our practice of rights risk condoning antagonism to both, and entering cautions about egalitarianism may engender elitism and other vulgar and destructive forms of class and personal pretension. Even skepticism about and determined suspicion of paternalism, authority, and powerdispositions that in my judgment are at the vital if restless center of liberalism - may diminish inclinations to serve and hence the likelihood of service.

Success in moving "toward a liberalism" might itself do something to mitigate or at least to defer all too familiar declensions such as these. To the extent that the ideas and themes I have introduced can be integrated into an encompassing, a unifying, construction, they might support one another so as to create resistance to the tendencies discussed in the previous paragraph. An idea that coheres with others, that "hangs together" with other ideas to form a system or a set, is perhaps less vulnerable to misconstruction and misuse. For example, in company with a suspicious stance toward authority and rules, and with a generalized skepticism about unqualified assertions and claims, arguments for moderating rights and for chastening attitudes toward the political role of citizenship may present a different appearance than those arguments have when encountered one by one.

If the themes of these essays do cohere, collecting them in this format might advantage the several arguments in these ways. Expressing this hope, however, brings me back to the beginnings of this introduction and indeed to the title of this work. I aim at "a" liberalism out of conviction, not diffidence or self-abnegation. Like love, liberalism is a many-splendored thing; also like love, the "manyness" of liberalism is integral to "its" splendor. In less florid terms, there is neither an exhaustive nor a privileged inventory of the ideas and themes of liberalism, and there is no reason to think that there is an indisputably superior ordering of any of the numerous sets and subsets of ideas that are recognizably or even arguably of a liberal character.

All thinking strains (however weakly) toward order, toward inte- 


\section{Introduction}

gration, toward system, and all theorizing seeks to magnify these tendencies of thought. Insofar as it self-consciously subscribes to and promotes an "ism," liberal thinking and theorizing intensify these characteristics of their genres. But it is fundamental to liberalism that none among the orderings its thinking and theorizing achieve can be regarded as exclusive, entire, or immutable. If achieving coherence and system meant realizing a closed, strictly hierarchical, or fully harmonious construction, coherence and system would be antithetical to liberalism and liberals would have to find other ways of coping with their difficulties. These essays concern elements in thought and action that I have come to value, not a dogma or doctrine; they identify and follow tendencies, but they do not march toward a fixed or even a clearly delineated destination. 